\title{
MAROSA DI GIORGIO, ÚLTIMA POETA DEL URUGUAY
}

\author{
POR \\ ROBERTO ECHAVARREN \\ Universidad de Nueva York
}

\section{LAS POETAS Y LA TRADICIÓN}

Delmira Agustini, María Eugenia Vaz Ferreira, Concepción Silva Belinzon, Amanda Berenguer, Ida Vitale, Idea Vilariño: he aquí algunas de las mujeres poetas del Uruguay. Un contingente numeroso si se lo compara con el de los hombres poetas durante el mismo período, es decir, desde el comienzo del siglo hasta nuestros días. No es que todas estas mujeres tengan algo en común, ni que reconozcan ellas mismas filiaciones comunes. La legislación liberal (ley de divorcio desde 1906) y el hecho de que la mayor parte de la población uruguaya (más del ochenta por ciento) viva en ciudades son factores que deben haber contribuido a esta eclosión de la escritura femenina. De entre las mujeres poetas me permito destacar a Marosa di Giorgio, la más joven de la serie, y, a mi entender, una de las más, si no la más, interesante. Di Giorgio empezó a publicar en los años cincuenta. En 1979 la editorial Arca, de Montevideo, reunió sus libros anteriores bajo el título de Los papeles salvajes. Después, Di Giorgio publicó La liebre de marzo (1981), La mesa de esmeralda (1985) y La falena (1987), volúmenes que aparecieron, también, en la editorial Arca. Di Giorgio tiene simpatía por la escritura de Delmira Agustini, Concepción Silva Belinzon, y Amanda Berenguer. Pero salvo reminiscencias ocasionales, la poesía de Di Giorgio presenta un cariz inconfundible. Yes notoria la cohesión de su trabajo, la continuidad del tono, de los procedimientos y del material anecdótico.

Algunos reseñadores periodísticos se han rebelado contra la consistencia de esta obra, como si pudiéramos reprochar a Gauguin o a Van Gogh el no ser tan versátiles como Picasso. Esos reseñadores han acusado a Di Giorgio de repetirse. A mí me parece, al contrario, que el explorar un territorio, el registro de variantes de una manera y un "mundo" es, aquí como en otros casos, el síntoma perentorio de un poder.

La obra de Di Giorgio no tiene nada que ver con los programas y los proyectos que se consideraban válidos en el Uruguay de los años sesenta, dominados por una poesía coloquial y "comprometida" que ofrece hoy, como entonces para los lectores exigentes, las marcas patéticas de su insuficiencia. 
Era una poesía que pretendía emplear el lenguaje "natural", o los giros típicos de un habla regional, localismos y pacto de la conversación, como si la lengua pudiese ser verdaderamente espontánea y trasparente. En Di Giorgio, en cambio, aflora una conciencia muy aguda del artificio, de la extravagancia, la burla y los disfraces. Lo familiar, en su obra, aparece como no familiar.

Pero esta poesía, que no paga derecho de piso, que no cede a un gusto timorato $o$ al temor de no comunicar inmediatamente con un público siempre más o menos imaginario, es una cuestión de sujeto y escritura: entabla el estatuto de la ficción a partir de un presente no ausente, no anquilosado, no obliterado de antemano por el cliché.

Uruguay no tuvo ni un Lezama Lima, ni un Borges, ni un Octavio Paz, ni un Vallejo, ni un Neruda, es decir, no tuvo un poeta fuerte de vanguardia. Sí tuvo, en la ficción, dos figuras cruciales: Juan Carlos Onetti y Felisberto Hernández. Pero el momento fuerte de la poesía uruguaya escrita en castellano fue el modernismo, con Delmira Agustini y el Julio Herrera y Reissig de La torre de las esfinges. La poesía uruguaya escrita en francés ya había tenido su momento culminante en la segunda mitad del siglo diecinueve, cuando los otros países latinoamericanos (salvo excepciones, como la Argentina con José Hernández), aún no tenían poesía digna de ese nombre. Isidore Ducasse (Lautréamont) y Jules Laforgue, gracias al hecho de escribir en francés y de pasar una parte de sus cortas vidas en Europa, proyectaron, como fundadores de la modernidad, sus trayectorias no sólo sobre el modernismohispanoamericano que intentó digerirlos, sino sobre el simbolismo y el surrealismo franceses, y, en el caso de Laforgue, sobre el modernismo angloamericano de T.S. Eliot. No me propongo trazar un árbol genealógico de Marosa Di Giorgio, sino alumbrar las relaciones letrales, las afinidades electivas sin las cuales su obra parece tan anómala como la del Presidente Schreber (con la cual se trazan, por lo pronto, otros paralelos). De Lautréamont, Di Giorgio hereda los rasgos animales o inhumanos, a ratos feroces, las transformaciones vertiginosas del yo lírico y de cualquier otra presencia o interlocutor, y la insensatez de un deseo sin cortapisas, intenso o violento, que tiene su campo de realización exagerada en lo increible-creible de la escritura, no en la "realidad". De Jules Laforgue, Di Giorgio hereda la pantalla complementaria de la luna, la superficie intocable sobre la que se reflejan los objetos platónicos de un apetito de insatisfacción, objetos contemplados por un prisionero en una caverna, bajo la luz de una linterna mágica.

En las páginas que siguen voy a referirme, por motivos prácticos, a uno solo de sus libros: La liebre de marzo. Las citas proceden de ese volumen.

\section{LA EXPERIENCIA (IN)SIGNIFICANTE}

Los textos de Di Giorgio son híbridos: están invariablemente construidos como pequeños poemas en prosa que, al encadenarse en una serie aleatoria, sugieren una novela poética. Pero es una novela fabulosa que derrota las 
expectativas antropomórficas. Lo que se anticipa, lo que ocurre, no es previsible según una perspectiva humanista o humanizadora. No suceden cosas entre los hombres (o entre los hombres y las mujeres), sino entre el yo lírico y animales, o plantas, o seres indefinidos, en un tono vehemente y categórico que da a la ficción un cariz alucinante. No se manifiestan sentimientos subjetivos, sino afectos impersonales, al margen de una identidad o un status social y de las relaciones intersubjetivas.

En esta mímesis inhumana, leemos que ciertas luces "brillaban con furia, con desesperación" ${ }^{1}$. La furia subraya la intensidad de la experiencia, cercana a un tope irresistible, y la desesperación sugiere una gratuidad insignificante. A pesar de ser intensos (furia), estos brillos no alcanzan a decir nada: lo único que podian hacer era brillar, en la inminencia de una revelación que no ocurre. El brillo implica una profecía que no llega como significado, no llega a tener significado. Espera constante: ocurren hechos que no terminan de entregar su secreto, y el testigo, o quien experimenta — un pronombre personal que anda por un borde roto, un yo de experiencias anómalas-generalmente no puede hacer nada con respecto a estos hechos, ni huir de ellos ni detenerlos 0 alterarlos ("un pajarillo totalmente azul volaba siempre en el mismo lugar al alcance de $\mathrm{mi}$ mano; no lo pude espantar ni cazar", 33) aunque hay intentos de que eso suceda, intentos retóricos del yo, de huir y no poder: "quiero despedirme, irme, pero fue inútil", "no podía irme", "no la podía abandonar". A veces-se corrige- hay pequeñas modificaciones: "con todo, me alejé un poco".

El trozo (citado arriba entre paréntesis, de la página 33) termina con un "quedé prendida a no sé qué y a nada". El no sé qué, la serie de brillos, no son nada, se prenden (y prenden a la narradora) y se apagan, entregan un parpadeo fuera del ser y la sustancia.

\section{LAS HOMOFONIAS}

$\mathrm{Si}$-en los poemas de Di Giorgio-se juega con aliteraciones, con homofonías significantes, las palabras de parecido sonoro surgen unas al lado de, o sustituidas por, otras, para quebrantar y desconcertar el flujo automático, embotado, del habla. Despiertan, revocan la ilusión de que el referente sea preciso oindiscutible; el narrador, el visionario, vacila al reconocer los elementos de la visión, al elegir las palabras para inventarla; las figuraciones indecisas se desprenden de la letra misma. Más que describir, se nota que el narrador va escogiendo (o perplejo, no puede escoger) entre parentescos sonoros, poniendo en peligro la continuidad metonímica de las escenas. Las homofonías ,como el chiste, según Freud, liberan de repente cierta energía, intiman un gozo eufórico. El discurso automático accede de repente, a través de sustituciones pérfidas,

\footnotetext{
${ }^{1}$ Marosa di Giongio, La liebre de marzo (Montevideo: Arca, 1981). En adelante, daré s6́lo la página de cada cita.
} 
estratégicas, interpuestas por el yo lírico, no a un significado definido, sino a un aura de goce. El habla filtra de repente los rayos que exaltan una voluptuosidad redescubierta.

Las homofonías "comedores, corredores" (33), "huesos, huevos" (34), introducen la duplicidad en los recorridos, traicionan o articulan una experiencia vacilante; proyectan el fragmento como una cascada fuera de foco: "andábamos por los oscuros comedores, corredores, y algún fugaz visitante sexual era atendido, o evitado, y clavelinas, tenebrarios tenebrarios, clavelinas, y más cosas". La homofonía distingue a partir de la cercanía, pero de la diferencia no deduce nada - no se sabe por qué el visitante sexual es atendido o evitado. El sumario diegético, el ciclo contrastivo, el ritornello, "clavelinas, tenebrarios" se repite, aunque se invierte el orden: invertir ya es variar el ritornello, pero sólo el último elemento - "más cosas" - consagra la variación, abre un panorama de alternativas indefinidas, descarrila el gesto o la frase que se repite. La repetición es dinamizada, desplazada de su carril familiar.

Las homofonías revelan que no hay sustancias, sino efectos superficiales del significante: "guardan huesos, huevos ... desde la cama los veía brillar" (34). El brillo apela (pero no conoce de seguro el nombre de lo que llama) como una mirada desafia al testigo para que la defina. El brillo, la mirada, deslumbran, dan cuerpo a la experiencia, aunque no la expliquen. Las homofonías marcan el máximo esfuerzo de atención hacia un enigma momentáneo, la atmósfera de un encuentro.

\section{EL ESPACIO}

¿Cómo se distribuye aquí el espacio? Lo que está dentro está fuera y viceversa. Los milagros ocurren dentro y fuera de las casas; "dentro" y "fuera" no son categorías que enmarcan la realidad, sino materiales para construir una escena conjetural de fogonazos, ronroneo de cosas, y afectos impersonales, curiosos o violentos. Más queidentidades, personajes ylugares, se experimentan climas, pasajes, ingredientes de una tormenta, una hora del día, velocidades y pausas, un "qué calor" o un "qué terribles cinco de la tarde", para evocar ejemplos, en esta vena, aducidos por Deleuze y Guattari. ${ }^{2}$ Climas y pasajes impersonales; no sentimientos de unyo frente a otros hombres. Al no subjetivarse, los afectos no oponen un adentro a un afuera, un interior orgánico y sentimental y un exterior otro. Intervienen quirúrgicamente a la narradora para extraerle las mismas cosas que, desde fuera, la acechan (cuerpo de mirada) “de bien adentro de mí sacan objetos monstruosos: relojes, muñecas, muchísimos dientes y peines, y huevos, huevos, huevos, azules, blancos y rosados, infinitamente, como si fuera una paloma de cuatro alas" (35). Un ángel, después de una vertiginosa

${ }^{2}$ Gilles Deleuze y Félix Guattari, Mille plateaux: capitalisme et schizophrénie (Paris: Minuit, 1980), 319. 
serie de trasformaciones, regresa al "alma" de la narradora, de donde había salido, y se muere (52). Viene de la nada, de un interior invisible, y vuelve a la nada. No hay sustancia de tales experiencias, ni un testigo con otra identidad que las vicisitudes circunstantes. No es posible huir de estas visiones -no hay salida, salvo velocidades y detenimientos-porque el perseguidoy el perseguidor están "contagiados" uno del otro, son inseparables: “¿No se me ocurrió cerrar los ojos? Igual, contemplo todo" (47).

\section{EL NEUTRO, EL OTRO}

El yo intenta a veces, pero inútilmente, separarse de un peligro, una dudosa amenaza, o una violencia. El yo, sin embargo, también es violento a veces, por ejemplo, cuandocome (un sargoque está vivo, y que la mira), pero, generalmente, no es responsable de sus violencias: la comida la prepara la abuela, $\mathbf{u}$ otros.

La agresión viril no se atribuye directamente al yo, ni siquiera a un hombre (o a una mujer), sino más bien a un animal, un tigre: "Y sentía temor y amor hacia el Maestro Tigre que llegaba en la noche a buscar doncellas" (71). La violencia es erótica, el erotismo violento, pero no tienen lugar a partir de relaciones entre seres humanos; no se describe un coito entre hombres, sino entre doncellas y tigres, entre un diablo o un lobo y otro personaje (a veces el yo victimizado).

Cuando el yo ataca, es, casi siempre, en tanto que otro. Cuando acecha y devora a un "niño de muy breve edad", se pone "el disfraz de lobo, el disfraz de león, los lentes de mariposa". Un yo disfrazado de león disfrazado - no de cordero, pero sí de incógnito bajo los lentes oscuros de la mariposa-star, bajo una máscara seductora. "Y la presa, ya, era presa" (67).

Pero a veces el perseguido persigue al perseguidor. Es como si la violencia fuese intercambiable, reversible. La tercera persona -según Blanchot-es el neutro, la no-persona, la persona despersonalizada, el borde anómalo de un recorrido. ${ }^{3}$ Aquí, atacar y ser atacado son bordes de un goce significado como tortura y crimen, cuando otro vive jugando con la muerte de alguien; la voluptuosidad de una violencia, la sospecha de un prodigio siniestro crecen y decrecen según una economía general, vivida como una serie de eventos singulares: no siempre se indica quién mata, quién muere, ni siquiera si alguien muere. Un asesino anónimo mata a las vacas, y es una violencia repetitiva, inacabable, que vuelve cada día: "Señor Dios, ¿no acabarán de morir, nunca?" (35). La experiencia que podríamos llamar, con Deleuze, del cuerpo sin órganos, ignora la muerte orgánica y el desfallecimiento individual, porque es una experiencia de lomúltiple, despersonalizada, nocorresponde a ningunaidentidad, unidad de persona: "No sé si moriré" (35). La mortalidad es una cuestión que

${ }^{3}$ Maurice Blanchot, "La voz narrativa", en El dialogo inconcluso (Caracas: Monte Avila, 1970), 587, 593-594. Traducción de L'Entretien infini (Paris: Gallimard, 1969). 
queda abierta, que no se puede resolver, pues la violencia, viva y aniquiladora, la agonía que tal cuerpo sin órganos experimenta, no es (todavía) muerte, sino exaltación anónima.

\section{SINIESTRO, SUBLIME}

Aunque el yo lírico es generalmente impotente para alterar las circunstancias, está lejos de contemplar impasible los fenómenos que lo acosan. Se sorprende, se asusta, tiene reacciones parangonables con las descritas por Freud cuando busca caracterizar la experiencia de lo no-familiar, de lo extraño descubierto en lo familiar, ${ }^{4}$ algo que según nuestra concepción adulta del orden del mundo, o de las leyes del cosmos, no puede ocurrir, y que sin embargo ocurre.

En este sentido, Freud cita a Jentsch, para quien lo siniestro es la incertidumbre acerca de que algo esté vivo o muerto, o la comprobación de que lo que parece muerto, vive, o viceversa. En Marosa:

Cazamos por segunda vez (y los pusimos en la anticísima asadera), uno de esos animales que están, al mismo tiempo, difuntos, vivos. Así, casi no es necesario violentarlos ... y la vida tiene un sabor extremo. Para subrayar tal festival se junta la sangre en los vasos y la sangre está también muerta y viva, pretérita $\mathrm{y}$ ardiente (53).

Lo difunto-vivo no es ficticio, sino que, no siendo cierto, ("y levemente no era cierto," escribe di Giorgio) "aún asi", de un cierto modo, es cierto. Lo figurado ocurre en una atmósfera de contagios fantásticos, de multiplicaciones animales, pero no se trata de un mero fantasma, sino de los devenires reales de un cuerpo. Los devenires son reales, aunque no son reales los resultados, los animales que se deviene..$^{5}$

Un "festival" mantiene, conjura, la atmósfera de incertidumbre: lo muertovivo es uno de sus rasgos. Los cuentos de Edgar Allan Poe ("Los hechos en el caso del Señor Waldemar", "Berenice", "Morelia", "La casa de Usher") suscitan la duda acerca de si los vivos están muertos, o los muertos vivos. Hay una vida en la muerte, en contraste con una muerte en vida, pero los dos estados se comunican, la experiencia resulta escandida por sorprendentes resurrecciones. Lo que en Poe es terror, en Marosa, sin eliminar la incertidumbre, deviene un gozo declarado. Los personajes de Poe se despiertan encerrados en un sarcófago. En Marosa también hay angustia, que llega tanto por el miedo a la intensidad de la vida, como por el hecho de que nada suceda, la noción de estar muerto en vida, de no producirse, de no experimentar sentimientos interpersonales,

\footnotetext{
${ }^{4}$ SigmundFreud, "Lo siniestro", en Obras completas, tomo III (Madrid: Biblioteca Nueva, 1973), 2483-2506. Traducción de "Das Unheimliche" (1919).

5 "El devenir animal del hombre es real, sin que sea real el animal que deviene". Deleuze y Guattari, op. cit., 291, traducción mía.
} 
antropomorfos, sino afectos cósmicos del cuerpo. Pero, muchas veces, esas experiencias exaltadoras ocurren con un mayor abandono, y un menor antropomorfismo, que en Poe.

Una de las aventuras eufóricas, en Marosa, es la del vuelo. Es una posibilidad olvidada que resurge. La posibilidad de vuelo es una convicción infantil descartada por el adulto. Por lo tanto, y como afirma Freud, el devenir niñoy la experiencia de lo siniestro se implican. Lo siniestro, según Freud, sería el resurgimiento de una creencia infantil. Lo que antaño resultó familiar, y que de algún modo sigue siéndolo, el adulto lo experimenta como no familiar:

Olvidé el primer vuelo. Lo recordaba apenas, y volvía a olvidarlo. Después, con la frecuencia, me vino cierta alarma. En el momento preciso, cuando todos duermen, salgo al cielo ... Aunque no hay nadie, saludo, me ro, hablo. Y también tengo zozobra, vergüenza, porque ¿qué es esto? ¿qué me sucede? (37)

Zozobra y alarma frente a un ejercicio que según la leyes del cosmos no es factible para el cuerpo de los humanos (falta el órgano, el ala). El que vuela se separa irremisiblemente de los otros hombres, que no vuelan. Del Sueño de Escipión, de Cicerón, hasta el "Sueño” de Sor Juana, el vuelo nocturno y onírico es un revés de las representaciones posibles, se abre un orden alternativo del mundo, no en balde ocurre de noche. No es una experiencia solar, sino lunar y estelar. César Aira, en Una novela china, ${ }^{6}$ describe al vuelo no como una etapa posterior en la historia, sino como algo que siempre estuvo allí. Es de acuerdo con Aira, algo así como una etapa primitiva de la pintura, aunque de hecho puede ocurrir después de las etapas no primitivas, o "adultas". El vuelo no es el resultado de una evolución, de una superación, ni tampoco es una regresión (decadencia, embotamiento) sino una "involución", ${ }^{7}$ un devenir niño, de la experiencia siniestra, cuando resurge una creencia descartada "lo más hermoso es ... ir con las alas bien blancas y abiertas, aunque creo que no tengo alas" (37, yo subrayo). Replantea la cuestión de la creencia, del "levemente no era cierto", del "no es cierto pero aún así ..." relevado por Octave Mannoni. ${ }^{8}$ El volar no es tener alas, sino un devenir pájaro, o devenir la Virgen Maria —que también vuela--: ni el pajaro ni la Virgen son resultados reales de la experiencia, pero la experiencia de devenir pájaro o Virgen sí es real.

El momento fantástico abre otro campo sin producir una explicación realista. Es un campo espectral, no porque contenga espectros, sino porque completa el espectro de la luz, agrega a la luz solar el revés de la luz nocturna. Di Giorgio jamás rompe el efecto siniestro, mantiene la incertidumbre.

\footnotetext{
- César Aira, Una novela china (Buenos Aires: Javier Vergara, 1987).

${ }^{7}$ Es el término que prefieren Deleuze y Guattari, 304.

- Octave Mannoni, "Ya lo sé, pero aún asi ...", La otra escena: claves de lo imaginario (Buenos Aires: Amorrortu, 1973), 9-27. Traducción de Clefs pour l'imaginaire, l'autre scène (París: Seuil, 1969).
} 
El poema es un preservativo, un glóbulo, una pantalla, un artículo del cuerpo, un aparato de goce, haciendo cuerpo en vez de los órganos. Ni la familia, ni la escuela, logran destruir esta función. La niña —un yo lírico ocasionalpasa por esas etapas y aún logra convertir a la madre en cómplice, a ella, a los amigos de la infancia, y a conocidos disfrazados ("los ojos de Félix Peyrallo"). Por más que los maestros, los padres, vigilen, examinen, no logran penetrar el misterio de las miradas, no las suyas, ni las que les dirige la niña, sino de las cosas y aún de alguna "muñeca" que "parecía inquirir ... ansiosa; vi que no podía decirle nada, que tal vez todo aquello 'fuera mentira', que figuraba en los libros como cuando 'no es cierto' ... sus ojos semejaban brillar de lágrimas" (22,). Poco importa que la visión común, que el dictamen de la enseñanza niegue la creencia. Sería muy difícil explicar este otro punto de vista, no es un punto de vista, no se trata de alucinar una pantalla únicamente, sino de recuperar un modo de percepción, una experiencia, con sus bandas de luz vibrante, su penetrabilidad. El o los juegos la hacen existir, mientras los exámenes de la escuela, el principio de realidad, niega la creencia, descarta experiencias que retornan con un acento no familiar, aparentemente desprendido.

Hay momentos de rabia y exasperación. La experiencia fantástica suele aparecer como una condena más que un beneficio, un acontecer irremediable que atenta contra el equilibrio, la supervivencia y los placeres antropomórficos: "Yo quedé harta de esa repetición, reverberación" (71), o:

¿Por qué no puedo ser una mujer y sí un hada? ... no tengo casa; me destinaron al arco iris; pero estoy harta de esa lista fresa y de esa otra verde. Cuando creo que puedo dar unos pasos por el suelo, y que algo, para mi, también, es cierto, allá en lo hondo del campo aparecen perros y gacelas y me mandan como guardia ... Creo dar algunos pasos en el suelo, creo que algo para mí también es cierto, pero, enseguida, está ese bosque, ese árbol que en cambio de hojas tiene perlas (82, yo subrayo).

No se trata de reemplazar la realidad por la ficción, sino de moverse en un devenir real de términos irreales: es real el devenir liebre, no la liebre. Cuando cuenta que puso un huevo, advierte: lo que había dentro del huevo no me lo pregunten, porque no lo sé; sólo sé que su sombra me persigue siempre.

Los devenires reales de la experiencia siniestra acosan al yo que se hace preguntas últimas: "Estoy sola, silba el viento, ¿adónde voy, adónde voy?" (78); o: "no se sabía qué pasaba, o no pasaba nada. Alturas que bramaban" (82). Alturas horribles, vertiginosas, del vuelo del alma, en Sor Juana ("gozosa mas suspensa, / suspensa pero ufana/y atónita aunque ufana", El sueño, versos 435437); tentación de la altura, o Anfaegtelse (en alemán, Anfechtung), en Temor y temblor de Kierkegaard, a propósito del pedido de Dios a Abraham de que sacrifique a su hijo Isaac. Tentación "inversa" a lo que, según el concepto teológico cristiano, sería la tentación demoníaca, o tentación de la carne: que tiende a una gratificación de los "instintos", copulación por placer, y satisfacción 
de las funciones orgánicas: beber, comer, orinar. A la narradora de La Liebre, al contrario, la "mandan como guardia, como estrella", a volar, ver a Dios, hacer la primera comunión devenir la Virgen. Tentación de la falta de gratificación, o deseo de insatisfacción. Aparte de la experiencia (mítica o mística, no menos real), no hay producto, o conclusión, o respuesta: "y jamás habrá respuesta" (78, 82).

En otras palabras: los brillos nómades, dudosamente definibles, ¿son una respuesta de qué, a qué? Dios tienta, escribe Kierkegaard, con la altura: temor y temblor frente a un peligro, un extremo. Equivale, en la Crítica del juicio, de Kant, al sublime dinámico, en que la violencia desatada de la naturaleza, o, podría agregarse ahora, la violencia desatada del hombre contra la naturaleza, amenaza la vida. Es, siempre, una tentación insensata, porque implica un riesgo de aniquilamiento. Pero el artista resiste, mantiene una lucidez calma al considerar las amenazas convincentes de su destrucción.

Dios o el demonio no son referentes objetivos, entes, sustancias, sino criterios diferenciadores que sirven para clasificar los tipos de tentación.

Me atrevo a sugerir la siguiente equivalencia: la tentación de lo bajo, o demoniaco, sería asimilable al plano que, en Freud, opone el principio de realidad al principio del placer. De cierto modo estos principios son enemigos, pero el principio de realidad es el instrumento de un placer posterior, es un desequilibrio trabajoso que busca culminar en la satisfacción de los sentidos, en el equilibrio u homeostasis orgánica. La tentación de lo alto, o divina, equival dría, por su parte, y en otro plano, al conflicto - en el Freud tardío- entre Eros y Tanatos, entre impulsos de la vida y de la muerte. La vida, aquí, es exaltada a una intensidad siniestra: el peligro es una ocasión para apreciar que aún estamos vivos, aunque divididos entre el placer y el goce, entre la tranquilidad y la intensidad, entre la sobrevivencia y la vida/muerte, al experimentar devenires que sobrepasan, o parecen sobrepasar, las capacidades orgánicas del cuerpo.

Pero esta distinción (entre alto y bajo, dios y el demonio) resultará, en rigor, adecuada dentro de un marco de ortodoxia teológica cristiana. Kierkegaard es un pensador cristiano que interpreta la tradición de lo sublime. Si lo sublime se origina en una lectura de las figuras poéticas de la poesía griega - y aún de la Biblia - por parte del falso Longino, esta lectura fue recuperada por la poética europea del siglo diecisiete, y alcanza uno de sus puntos culminantes en la Crítica del juicio de Kant. Para esta tradición poética el demonio adquiere un rango sublime, tanto como Dios. Movimiento que se esboza en la poética del desastre y la acentuación de figuras mitológicas de ambición excesiva y autodestructora: Icaro, Faetón (en Góngora, Villamediana, Sor Juana Inés de la Cruz), o el Lucifer de Milton. En el siglo diecinueve, Los cantos de Maldoror, o Una temporada en el infierno representan la tradición maldita del desafío sublime a Dios.

Tampoco en Di Giorgio hay una distinción valorativa -en cuanto al rasgo sublime o siniestro- entre dios y el demonio. La tentación de lo alto - 
llamémosla así, tanto divina como demoníaca - no lleva a gratificaciones "literales". Un menú en La liebre consiste en manjares apenas comestibles escasamente alimenticios, incapaces de calmar el apetito: "algunos pedían luciérnagas que era lo más caro. Otros mariposas gruesas color crema con una hoja de menta y un minúsculo caracolillo. Y recuerdo cuando servimos a aquella gran mariposa negra, que parecía de terciopelo, que parecía una mujer" (18). Tienta con un gozo equivalente a la tortura, a la agonía. Entrega una información ambigua, no garantiza la satisfacción de una necesidad. El plan de explicación fracasa, pero ese fracaso equivale a la deriva de escribir, a las transformaciones del material significante. El objeto placentero se define de manera bien clara y su consumo implica una satisfacción (apagar la sed), mientras el objeto del deseo es inasible, oscuro, insatisfactorio.

\section{EL SOL Y LA LUNA}

En este aura siniestra (o paradójica) el colmo es que la luz del sol y la luz lunar sean una, parezcan una, sean la misma. Un libro de Laforgue lleva el título Imitation de Notre Dame la Lune, alusión retomada por Lugones en el Lunario sentimental. Sobre la luna, superficie, pantalla de proyección inasible, aparecen cosas que no gratifican, porque son tan intocables como la luna. Esa luz, ficción o fantasmagoria, intima lo imposible, en oposición a la luz del sol, plenamente física, quemante, que nutre las funciones orgánicas. Pero en su punto culminante, la luz de la luna adquiere una contundencia equivalente a la del sol, o se contamina de sol, el sol de la mano que escribe (Lezama), el sol del cuerpo: "Por un segundo la luz lunar y la del sol parecen una" (49).

La luna casi triunfa sobre el sol, o al menos se equipara en intensidad o valencia. Este es el momento de máxima credibilidad de la fantasmagoría, experiencias de intensidad cuasi alucinatoria del cuerpo sin órganos.

\section{LA MIRADA}

Los brillos (en, de, las cosas) se captan como miradas, que sin embargo no miran: siniestras. Equiparables a la experiencia que Baudrillard considera americana, ${ }^{9}$ de entrar a un cuarto sin nadie donde hay un televisor encendido: el televisor es la mirada de nadie, una mirada sin persona, ni viva ni muerta; o muerta y viva a la vez. En Marosa: "la lamparilla roja andando, toda mi larga infancia, miró a todos, y a mí más que a ninguno, como si quisiera enseñarme un secreto muy antiguo y una cosa abominable” (64).

El borde, el yo anómalo de estas experiencias, descubre que lo están mirando, pero la mirada que recae sobre el yo es ciega: “El dios del maíz era del tamaño

\footnotetext{
- Jean Baudrillard, América (Barcelona: Anagrama, 1987), 72. Traducción de Amérique (Paris: Grasset, 1986).
} 
de un gato, un poco más grande ... ojos sesgados y blancos, sin iris ni pupilas. Era lo único que veíamos cuando la noche pasaba ..." (59). Lo único visible son los ojos que no miran, porque no tienen ni iris ni pupilas para mirar. En Una novela china, el dragón, en la noche, no es sino una reverberación de florcitas blancas, el rebrillo vidrioso de un culebreante invernadero bajo la luz de la luna: "Luz engañosa ... el dragón no mira ... es una pura presencia lumínica, ni siquiera acecha"; su aparecer equivale al dar vuelta el propio ojo como si fuera un guante; es el revés del ojo: "La noche, niña, es lo que está en el fondo de una mirada, y las miradas son las fundas de la luz, que se dan vuelta siempre al sacarlas, por eso la noche y el dragón siempre están apareciendo ${ }^{n} .^{10}$

La Virgen, cuando, en La liebre, aparece, tampoco mira al yo: "no era que me mirase, ella miraba hacia abajo, hacia adelante" (71).

\section{LOS NO-PERSONAJES}

Aparecen muchas Vírgenes, pero no habrá que preguntarse por la sustancia teológica, mítica, o personal, de la aparición, sino más bien con qué se fabrica, qué materiales o ingredientes hacen Virgen'; no retratos de la Virgen, sino sus pasajes, sus gestos: una dinámica del efecto Virgen: "La luna es a cada minuto más blanca y oscura, y resplandece por todo el prado, aquí y allá, la Virgen de los Insectos, con ala, y diadema, y muchísimos pies" (57). No hay identidad compartida entre las diferentes Vírgenes, sino un nombre que señala una atmósfera, un "del costado de Guermantes", o un ciclón. No mitología, sino cuentos de Virgen, una literatura menor de las Vírgenes; a cada paso la Virgen es otra cosa; no representa papeles diversos, porque la Virgen no juega ni uno ni varios personajes: sino representa aconteceres, de pronto y por todos lados, ubicua fosforescencia.

La madre ("mamá", nombrada con frecuencia) es, en algunos lugares, censora; requiere del yo comportamientos conformes, decoro, silencio, pero la censura es más una broma, una estratagema dinámica; la madre se hace cómplice de las fechorías o transgresiones en el terreno donde, en rigor, no hay personajes, no hay identidades, porque no "había nadie", sino voces de muchas cosas, estallidos, vientos, silencios. También ella, la madre, ve -aunque simule nover-a los ángeles y a las Vírgenes, prodigios minerales, vegetales, o animales en la granja, y es prodigio ella misma, fragmentada en mil ojos, como Argos, como un Rey: "ella parece reírse sola, y reaparece otra vez, por todas partes" (55). Las cosas dejan de tener un lugar: las apariciones acechan por todas partes y sobrecogen, cuasi superficie, cuasi piel: cuando ya no hay nadie, hay cuerpo, espesor de un cuerpo sin órganos.

El protagonista no es una persona, sino un acontecimiento; a saber, las "heladas" (o, como anota Deleuze, un tifón, o una tarde): ${ }^{11}$

\footnotetext{
${ }^{10}$ César Aira, 156-157.

${ }^{11}$ Deleuze y Guattari, 318-319.
} 


\begin{abstract}
¿Quién se va a olvidar de las heladas, cuando el agua se volvía de vidrio, con una naranja dentro, como una estrella? Mi madre andando en una caparazón de vidrios, los árboles y los hombres bajo capotes trasparentes. Corrían penitas en las cosas. El sol con su luz rojiza dorada, y la luna al lado, con su luz celeste, y pasan carros, ánimas con muchisimas alas, todas blanquísimas. Nos miramos y hay un gran peligro de invierno para cada uno (69-70).
\end{abstract}

Devenir, combinarse, y diferenciarse de elementos a partir del esplendor indistinto pero conminatorio de un "recuerdo": más bien un trampolín para la invención. El trozo comienza con una evocación del pasado y termina en una anticipación del futuro. Pero algo no termina de decirse, oscuro, conjetural, entreoído:

Dijo "mariposa", "Amelia", y me volvi en el aire oscuro de la tarde de oro ... era el dios que hablaba, era el puma, me volví buscando su cara de oro, su invisible huella. Mas: nada había. Sólo el viento, que jugaba, como siempre ... (70).

El dios, el puma, o el demonio: nadie habla, algo habla, las voces divinas, las voces de los pájaros y de los otros animales, fantasmagoría garantizada por las velocidades, por las intensidades, de un ciclón, de un viento, de un cuerpo sin identidad, múltiple, cósmico. Esporádicas, intermitentes ráfagas o harapos de voces, se atribuyen a los soportes menos verosímiles: las vacas, las papas, las gallinas, constante prosopopeya en que cualquiera habla, desde cualquier parte: "los animales hablaban, las vacas y caballos de mi padre, sus aves, sus ovejas: largos raciocinios, parlamentos, discusiones entre sí y con los hombres" (46) ... "y algunas gallinas de sombrero rojo, que hablaban de continuo" (42).

En Di Giorgio, la palabra de los dioses, las plantas y los animales ("esa papa rezonga algo; le contesta, con su boca de fuego, aquella rosa") alterna con un ruido confuso ("no entendí bien ... había un murmullo increŕble en cada cosa", 72). Los significantes no se entienden, o las cosas no (se) terminan de figurar: "y en la mano no se qué (84) recuerda a San Juan de la Cruz: "un no sé qué que quedan balbuciendo". La poesía no apunta a un más de significación, sino que se tambalea y bordea siempre un menos, un borramiento. El simbolismo poético corroe, como en los intentos fracasados de Baudelaire (soneto de las correspondencias), el plan de clasificación se marea y naufraga en un perfume.

\title{
EL COITO
}

El coito, cuando ocurre, suele ser "consigo mismo", autogoce y autofecundación: "casada consigo mismo" (82). Dos trozos se refieren a las intimidades complementarias del hermafrodita, designado, para darle un pronombre, por "ellas":

se sabe de ellas que tienen relaciones consigo ... y se las ve en el espasmo, o rígidas como un dedo alcanzan a beber en la fuente de las rosas; están 
emparentadas con las rosas, las bromelias, y el peral; las consideran sólo en sueños representación de los pecados de los hombres ... pero yo de niñita, a la luz del sol y de la luna, creo en ellas, sé que son de verdad (64).

Por sí, sin partenaire, alcanzan un goce, un momento turbador. Representan lo que resulta (im)posible alcanzar, sublime materia de creencia. Dejan de estar en suspenso para el yo que deviene niño y tiene fe, $\mathrm{y}$, protegido por la luna, afianza la faz del sol: " las vi ... en el amor, a solas, retorcerse hasta morir" (6566).

Las fecundaciones no tienen que ver con un apareamiento, con la operación de los órganos genitales. Más bien ocurren por contagio, contaminaciones aéreas, coincidencias mágicas, magnetismo, simpatías, influjos: "se reproducen sin tocarse".

El caracol es el emblema de la (in)decisión e (in)suficiencia del goce: "el caracol ... camina como un señor, una señorita de los cielos”. Recuerdo a Marco Antonio Ettedgui: "se me pasa de hombre a mujer, basta un parpadeo, un ruido en su terminología". ${ }^{2}$ Para Di Giorgio, el caracol "es a la vez el señor y la señorita; en ese pedacito blanco están Hermes y Afrodita; así se detiene y se conjuga, solo, y luego del segundo perturbador, prosigue ...” (66). Este es el misterio al que se asoman constantemente los textos de Marosa: el autogoce, fitrado en el rejuego de una tentación terrible, por furiosa y por desesperada. Lo otro aparece como lo familiar, y viceversa. Momentánea omnipotencia del devenir caracol, donde cuaja, o se desprende, el espesor corporal: página, piel, membrana gozosa que, al tensionarse, no se corresponde, no equivale, a tal o cual función particularizada de los órganos.

${ }^{12}$ Marco Antonio Ettedgui, Arte-información para la comunidad (Caracas: Oxígeno, 1985), 31 . 
